\title{
Quorum sensing signals are produced by Aeromonas salmonicida and quorum sensing inhibitors can reduce production of a potential virulence factor
}

\author{
Maria Rasch ${ }^{1}$, Vicky Gaedt Kastbjerg ${ }^{1}$, Jesper Bartholin Bruhn' ${ }^{1}$, \\ Inger Dalsgaard ${ }^{2}$, Michael Givskov ${ }^{3}$, Lone Gram ${ }^{1, *}$ \\ ${ }^{1}$ Danish Institute for Fisheries Research, Department of Seafood Research, Technical University of Denmark, Søltofts Plads \\ bldg. 221, 2800 Kgs. Lyngby, Denmark \\ ${ }^{2}$ Danish Institute for Fisheries Research, Fish Disease Laboratory, Technical University of Denmark, Stigbøjlen 4, \\ 1870 Frederiksberg C, Denmark \\ ${ }^{3}$ Center for Biomedical Microbiology, BioCentrum, Technical University of Denmark bldg. 301, 2800 Kgs. Lyngby, Denmark
}

\begin{abstract}
Many pathogens control production of virulence factors by self-produced signals in a process called quorum sensing (QS). We demonstrate that acyl homoserine lactone (AHL) signals, which enable bacteria to express certain phenotypes in relation to cell density, are produced by a wide spectrum of Aeromonas salmonicida strains. All 31 typical strains were AHL producers as were 21 of 26 atypical strains, but on a strain population basis, production of virulence factors such as protease, lipase, A-layer or pigment did not correlate with the production and accumulation of AHLs in the growth medium. Pigment production was only observed in broth under highly aerated conditions. Quorum sensing inhibitors (QSIs) are compounds that specifically block QS systems without affecting bacterial growth and 2 such compounds, sulphur-containing AHL-analogues, reduced production of protease in a typical strain of Aeromonas salmonicida. The most efficient compound $N$-(heptylsulfanylacetyl)-L-homoserine lactone (HepS-AHL), reduced protease production by a factor of 10 . Five extracellular proteases were detected on gelatin-containing sodium dodecyl sulphate polyacrylamide gel electrophoresis (SDS-PAGE) gels and 3 of these were completely down regulated by HepS-AHL. Hence, QSIs can curb virulence in some strains and could potentially be pursued as bacterial disease control measures in aquaculture.
\end{abstract}

KEY WORDS: Acylated homoserine lactones · Aeromonas salmonicida · Pigment · Protease · Quorum sensing inhibitors

\section{INTRODUCTION}

Fish farming is an intensive production and microbial diseases may occur. Traditionally, antibiotics or chemotherapeutics have been used to control microbial diseases, but this may lead to resistance in both pathogenic and non-pathogenic bacteria (Tsoumas et al. 1989, Spanggaard et al. 1993, Depaola et al. 1995, Schmidt et al. 2000). The use of antibiotics has been dramatically reduced by development and use of vaccines (Grave et al. 1996, Markestad \& Grave 1997, NORM-VET 2004); however, vaccines cannot be used at all stages and for all aquacultured species. Research has, therefore, also focused on alternative, potential disease control measures such as probiotics (Gram \& Ringø 2005) or specific attenuators of bacterial virulence (Hentzer et al. 2003).

Some Gram-negative bacteria regulate their virulence factors as a function of population cell density (quorum sensing, QS), which they sense by means of extracellular signal molecules such as acylated homoserine lactones (AHLs). QS systems and/or QS signals have been found in many Gram-negative fish pathogenic bacteria such as Aeromonas hydrophila, A. salmonicida, Vibrio harveyi, $V$. anguillarum, V. salmonicida, V. vulnificus, Edwardsiella tarda and Yersinia ruckeri (Milton et al. 1997, Swift et al. 1997, Freeman \& Bassler 1999, Temprano et al. 2001, Buch et al. 2003, Morohoshi et al. 2004, Bruhn et al. 
2005). QS controls several of the putative virulence factors in aquatic bacteria, such as protease in $V$. anguillarum (Croxatto et al. 2002) and A. hydrophila (Swift et al. 1999), siderophores in $V$. harveyi (Lilley \& Bassler 2000), and haemolysin in $V$. vulnificus (Kim et al. 2003). However, the role of the QS systems in expression of virulence in fish pathogenic bacteria is not at present fully understood.

Quorum sensing inhibitors (QSIs) are compounds that antagonise bacterial QS systems without affecting growth of the bacteria (Smith et al. 2003, Castang et al. 2004, Persson et al. 2005, Rasmussen et al. 2005a,b). QSIs reduce production of toxin from Vibrio harveyi (Manefield et al. 2000) and treatment with a QSI, the halogenated furanone C-30, reduced accumulated mortality in rainbow trout infected with $V$. anguillarum (Rasch et al. 2004). However higher concentrations of furanone $\mathrm{C}-30$ resulted in rapid fish death (Rasch et al. 2004), which stressed the need to explore less toxic QSI compounds for treatment. Sulfonated analogues of AHL compounds are such less toxic compounds (Persson et al. 2005) and can inhibit several QS systems (Koch et al. 2005). In the present study, we address the possible involvement of QS systems in expression of virulence factors of Aeromonas salmonicida and determine to what extent QSI compounds affect production of virulence factors.

Aeromonas salmonicida is the bacterial agent associated with furunculosis in salmonid fish (Austin \& Austin 1999). The QS signals, $N$-butanoyl-L-homoserine lactone $\left(\mathrm{C}_{4}\right.$-HSL) and $N$-hexanoyl-L-homoserine lactone ( $\mathrm{C}_{6}$-HSL) (Swift et al. 1997, Bruhn et al. 2005), and the genes involved in production of the AHL synthase (LuxI) and AHL receptor (LuxR) have been detected in A. salmonicida (Swift et al. 1997). Several of the virulence factors expressed by A. salmonicida, such as $\alpha$-haemolysin, glycero-phospholipid-cholesterol acyltransferase, lipase and serine protease, are associated with high cell densities and may therefore potentially be controlled by QS (Swift et al. 1997). Exogenous addition of $\mathrm{C}_{4}$-HSL resulted in a small induction of protease production in A. salmonicida, whereas addition of $N$-decanoyl-L-homoserine lactone $\left(\mathrm{C}_{10}\right.$-HSL) and $\mathrm{N}$-(3-oxodecanoyl)-L-homoserine lactone (oxo- $\mathrm{C}_{10}-\mathrm{HSL}$ ) inhibited protease production (Swift et al. 1997). Both the induction by the natural AHL compound and inhibition by longer chained compounds indicate that the protease is under QS control.

Bruhn et al. (2005) reported that AHLs were produced by all of 7 typical Aeromonas salmonicida strains but only in 2 of 10 atypical strains (A. salmonicida ssp. pectinolytica DSM 12609 and A. salmonicida ssp. achromogenes NCIMB 1110). Typical strains (ssp. salmonicida) and ssp. pectinolytica produce a brown water-soluble pigment whereas atypical strains (ssp. achromogenes, ssp. masoucida, and ssp. smithia) produce only very low amounts of the brown pigment (Wiklund \& Dalsgaard 1998, Pavan et al. 2000). The AHL production was only observed from strains producing the pigment (J. B. Bruhn unpubl.). Hence, we hypothesised that pigment and AHL production could be correlated and investigate this in a larger collection of strains in the present study.

The purpose of the present study was to investigate whether there is any correlation between production of QS signal molecules and virulence factors in Aeromonas salmonicida and if there are systematic differences in QS signal production in typical and atypical strains. Furthermore, the possible effect of a series of new QSIs on production of virulence factors in $A$. salmonicida was investigated with the long-term aim of evaluating their potential use in control of fish disease.

\section{MATERIALS AND METHODS}

Bacterial strains and culture conditions. A selection of 31 typical and 26 atypical Aeromonas salmonicida was used in this study (see Tables $1 \& 2$ ). The strain collection comprised strains isolated over many years from different sources, locations and from both sea and freshwater farms as well as type strains. All but 3 strains had been stored at $-80^{\circ} \mathrm{C}$ immediately after isolation. All strains were grown in Luria-Bertani broth (Bertani 1951) using $5 \mathrm{~g} \mathrm{l}^{-1}$ of $\mathrm{NaCl}$ instead of $10 \mathrm{~g} \mathrm{l}^{-1}\left(\mathrm{LB}_{5}\right)$. When appropriate, the broth was supplemented with $1.2 \%(\mathrm{w} / \mathrm{v})$ agar. AHLs were monitored using Agrobacterium tumefaciens strain NT1 with pZLR4 (Cha et al. 1998) and Chromobacterium violaceum strain CV026 (Throup et al. 1995, McClean et al. 1997). The growth media for A. tumefaciens and $C$. violaceum were supplemented with $20 \mathrm{\mu g} \mathrm{ml}^{-1}$ of gentamicin and kanamycin, respectively. A. tumefaciens was grown in $A B$ medium (Clark \& Maaløe 1967) supplemented with $2.5 \mathrm{mg} \mathrm{l}^{-1}$ thiamine (ABT), $0.5 \%$ $(\mathrm{w} / \mathrm{w})$ casamino acids and $0.5 \%(\mathrm{w} / \mathrm{w})$ glucose (ABTG) for estimation of levels of AHLs.

Production of virulence factors. Protease production and proteolytic activity was detected on $1.2 \%$ agar plates supplemented with $10 \%(\mathrm{v} / \mathrm{v})$ sterile skimmed milk ( $105^{\circ} \mathrm{C}$ for $\left.30 \mathrm{~min}\right)$. The cultures were streaked on the skim milk agar plates and incubated at $25^{\circ} \mathrm{C}$. Proteolytic strains caused a clearing zone around the bacterial growth. Quantitative assessment of protease production was assayed in sterile filtered culture supernatants (Windle \& Kelleher 1997, Denkin \& Nelson 1999). In brief $100 \mu \mathrm{l}$ of sample was incubated with $100 \mu \mathrm{l}$ azocasein (sulfanilamide-azocasein, cat. no. A-2765, Sigma) (5 mg $\mathrm{ml}^{-1}$ dissolved in $50 \mathrm{mM}$ Tris $-\mathrm{HCl}, \mathrm{pH}$ 8) at $30^{\circ} \mathrm{C}$ for $90 \mathrm{~min}$. The reaction was terminated by addition of $400 \mu \mathrm{l}$ trichloracetic acid $(10 \% \mathrm{w} / \mathrm{v})$ and the precipitated 
protein was removed by centrifugation $(16000 \times g$, $3 \mathrm{~min})$. We transferred $500 \mu \mathrm{l}$ supernatant to $700 \mu \mathrm{l}$ of $525 \mathrm{mM} \mathrm{NaOH}$ and measured optical density (OD) at $442 \mathrm{~nm}$ on a Novaspec II visible spectrophotometer (Pharmacia Biotech). Each sample was assayed in triplicate and 2 controls were prepared for each sample. Controls were vials to which the sample was added after trichloracetic acid. Protease profiles were analysed by electrophoresis of sterile filtered culture supernatants on zymogram gels (ready gel zymogram gel $12 \%$ with casein, cat. no. 161-1114, and ready gel zymogram gel $10 \%$ with gelatin, cat. no. 161-1113, Bio-Rad). Protease size was determined by using a dual colour molecular weight standard (Precision Plus Protein Standard cat. no. 161-0374, Bio-Rad), which was cut off the gel before staining with Coomassie Brilliant Blue (CBB) R-250 (cat. no. 443283M, BDH) (Rajmohan et al. 2002). Lipase activity was assayed on tributyrin agar (cat. no. PM0004C, Oxoid). We spotted $10 \mu \mathrm{l}$ of an overnight culture on the agar plates, and the plates were incubated at $25^{\circ} \mathrm{C}$ until visible growth. Lipolytic activity was seen as clear zones around the colonies. Pseudomonas aeruginosa ATCC 27853 was used as positive control and Escherichia coli MG1655 as negative control for lipolytic activity. Presence of A-layer was evaluated on CBB agar (Bernoth 1990). Cultures grown in $\mathrm{LB}_{5}$ were streaked on CBBplates and incubated at $20^{\circ} \mathrm{C}$ and presence of A-layer was seen as blue colonies whereas A-layer negative strains had white colonies. For strains with both blue and white colonies on the plates the proportion of blue vs. white colonies was estimated. For quantitative evaluation of pigment production, sterile filtered bacterial supernatants were measured spectrophotometrically on as Novaspec II visible spectrophotometer (Pharmacia Biotech) at $410 \mathrm{~nm}$ with the appropriate growth medium as reference. The cultures were grown in $50 \mathrm{ml} \mathrm{LB}_{5}$ broth in $250 \mathrm{ml}$ bottles covered with oxygen permeable film at $200 \mathrm{rpm}$ on a rotational shaker at $15^{\circ} \mathrm{C}$.

Production of QS signals, acylated homoserine lactones. The Aeromonas salmonicida strains were streaked on a $\mathrm{LB}_{5}$ agar plates (without added antibiotic) in parallel with each of the monitor strains Agrobac-

Table 1. Aeromonas salmonicida. Production of virulence factors and acylated homoserine lactones (AHLs) in typical strains. Protease activity detected on casein agar; A-layer detected on Coomassie Brilliant Blue (CBB) agar; pigment in Luria-Bertani broth using $5 \mathrm{~g} \mathrm{l}^{-1} \mathrm{NaCl}\left(\mathrm{LB}_{5}\right)$ at $15^{\circ} \mathrm{C}$ measured as optical density at $410 \mathrm{~nm}$ after $7 \mathrm{~d}$ growth; lipase detected on tributyrin agar; AHLs detected with Chromobacterium violaceum CV026, and Agrobacterium tumefaciens pZLR4. Sea: sea farm; Fresh: freshwater farm. + : positive; $(+)$ : slightly positive; - : negative $;+$ /- majority positive

\begin{tabular}{|c|c|c|c|c|c|c|c|c|}
\hline \multirow[t]{2}{*}{ Strain } & \multirow[t]{2}{*}{ Source } & \multirow[t]{2}{*}{ Location } & \multirow[t]{2}{*}{ Protease } & \multirow[t]{2}{*}{ A-layer } & \multirow[t]{2}{*}{ Pigment } & \multirow[t]{2}{*}{ Lipase } & \multicolumn{2}{|c|}{ AHL production } \\
\hline & & & & & & & CV026 & pZLR4 \\
\hline NCIMB 1102 & Atlantic salmon & Scotland & + & + & 6.56 & + & + & + \\
\hline $02-9-1$ & Rainbow trout & Denmark; Sea & + & $+/-$ & 6.38 & + & + & + \\
\hline $02-9-37$ & Rainbow trout & Denmark, Sea & + & + & 7.26 & + & + & + \\
\hline $93-8-294$ & Rainbow trout & Denmark, Sea & + & + & 6.12 & + & + & + \\
\hline $94-6-87$ & Rainbow trout & Denmark, Sea & + & + & 6.12 & + & + & + \\
\hline ATCC 14174 & Brook trout & USA & - & - & 6.48 & + & + & + \\
\hline $820615-1 / 2$ & Rainbow trout & Denmark, Sea & - & + & 4.70 & - & + & + \\
\hline 820618-2/1 & Rainbow trout & Denmark, Fresh & - & + & 5.78 & + & + & + \\
\hline $830608-1 / 2$ & Rainbow trout & Denmark, Fresh & + & - & 7.28 & + & + & + \\
\hline $830719-2 / 2$ & Rainbow trout & Denmark, Sea & + & + & 6.76 & + & + & + \\
\hline $830803-1 / 2$ & Rainbow trout & Denmark, Sea & + & + & 6.96 & + & + & + \\
\hline $850612-1 / 1$ & Rainbow trout & Denmark, Sea & - & + & 5.48 & + & + & + \\
\hline $850613-1 / 1$ & Rainbow trout & Denmark, Sea & + & - & 7.10 & + & + & + \\
\hline $860619-3 / 3$ & Rainbow trout & Denmark, Sea & + & + & 6.80 & + & + & + \\
\hline $860815-1 / 2$ & Rainbow trout & Denmark, Sea & + & - & 6.96 & + & + & + \\
\hline $870708-1 / 4$ & Rainbow trout & Denmark, Fresh & + & + & 6.18 & $(+)$ & + & + \\
\hline $880819-2 / 1$ & Rainbow trout & Denmark, Fresh & + & + & 6.14 & + & + & + \\
\hline $880827-1 / 2$ & Rainbow trout & Denmark, Sea & + & + & 7.14 & + & + & + \\
\hline $940818-1 / 1$ & Rainbow trout & Denmark, Sea & + & + & 5.88 & + & + & + \\
\hline $950901-3 / 1$ & Rainbow trout & Denmark, Fresh & - & + & 5.10 & + & + & + \\
\hline $960828-1 / 1$ & Rainbow trout & Denmark, Sea & + & + & 7.18 & + & + & + \\
\hline $980623-1 / 1$ & Sea trout & Denmark, Fresh & + & + & 5.46 & - & + & + \\
\hline $990622-1 / 9$ & Sea trout & Denmark, Sea & + & + & 4.66 & + & + & + \\
\hline 020625-6/2 & Common whitefish & Denmark, Fresh & + & + & 5.30 & + & + & + \\
\hline 030715-1/8 & Common whitefish & Denmark, Fresh & + & + & 6.12 & + & + & + \\
\hline 030729-1/1 & Rainbow trout & Denmark, Sea & + & + & 5.20 & + & + & + \\
\hline $040115-2 / 2$ & Atlantic salmon & Denmark, Fresh & + & + & 5.88 & + & + & + \\
\hline 040811-1/2 & Charr & Denmark, Fresh & + & + & 4.94 & + & + & + \\
\hline $040915-1 / 2$ & Rainbow trout & Denmark, Sea & + & + & 5.60 & + & + & + \\
\hline $050225-1 / 1 \mathrm{~A}$ & Atlantic salmon & Denmark, Fresh & + & + & 5.80 & + & + & + \\
\hline Jno 3175/88 & Atlantic salmon & Norway & + & + & 6.80 & + & + & + \\
\hline
\end{tabular}


terium tumefaciens and Chromobacterium violaceum as described by Ravn et al. (2001). A. tumefaciens plates were supplemented with X-gal (5-bromo4-chloro-3-indolyl $\beta$-D-galactopyranoside, cat. no. A4978, AppliChem) to a final concentration of $50 \mu \mathrm{g}$ $\mathrm{ml}^{-1}$. The plates were incubated at $25^{\circ} \mathrm{C}$ until both strains showed good growth. Aeromonas strains causing blue colour in A. tumefaciens or violet pigmentation in C. violaceum were positive for AHL production. Semiquantitative determination of AHL concentrations was determined by testing extracts of liquid cultures in a well diffusion assay (Ravn et al. 2001) with $\mathrm{C}_{4}$-HSL (cat. no. 09945, Sigma-Aldrich) as standard. We lowered $25 \mathrm{ml}$ of bacterial cultures to $\mathrm{pH} 2$ with $2 \mathrm{M} \mathrm{HCl}$ to ensure that the lactone ring of the AHL molecule was closed. The culture was extracted with an equal volume of acidified ethyl acetate (ethyl acetate with $0.5 \%$ formic acid). The mixture was shaken vigorously and after phase separation, the ethyl acetate phase was transferred, evaporated under nitrogen flow and redissolved in $1 \mathrm{ml}$ of acidified ethyl acetate. The samples were stored at $-20^{\circ} \mathrm{C}$ until further analyses.
Growth experiments. Aeromonas salmonicida strain 02-9-1 was isolated from a furunculosis outbreak in salmon. It produces extracellular virulence factors including a high level of pigment. The strain produces several AHLs with $\mathrm{C}_{4}$-HSL as the dominant molecule (called 'BHL' in Bruhn et al. 2005). Strain 02-9-1 was cultured on $\mathrm{LB}_{5}$ agar and inoculated in $50 \mathrm{ml} \mathrm{LB}_{5}$ broth at $15^{\circ} \mathrm{C}$ and $200 \mathrm{rpm}$ for $2 \mathrm{~d}$. We inoculated $2000 \mathrm{ml}$ baffled flasks with $1500 \mathrm{ml}$ of $\mathrm{LB}_{5}$ with $A$. salmonicida 02-9-1 to a final concentration of approx. $10^{3} \mathrm{CFU} \mathrm{ml}^{-1}$. The flasks were incubated at $15^{\circ} \mathrm{C}$ and $200 \mathrm{rpm}$. At appropriate time intervals samples were taken for measurement of cell density $\left(\mathrm{OD}_{450 \mathrm{~nm}}\right), \mathrm{CFU} \mathrm{m} \mathrm{m}^{-1}$ on $\mathrm{LB}_{5}$ agar, and pigment production as described above. AHLs were extracted as described above, and sterile filtered culture supernatants were stored at $-20^{\circ} \mathrm{C}$ for further analysis of protease activity and protease profiles.

Effect of QSI compounds on growth and protease production. The QSI compounds $N$-(propylsulfanylacetyl)-L-homoserine lactone (ProS-AHL), N-(pentylsulfanylacetyl)-L-homoserine lactone (PenS-AHL) and

Table 2. Aeromonas salmonicida. Production of virulence factors and acylated homoserine lactones (AHLs) in atypical strains. Protease activity detected on casein agar; A-layer detected on Coomasie Brilliant Blue (CBB) agar; pigment in Luria-Bertani broth using $5 \mathrm{~g} \mathrm{l}^{-1} \mathrm{NaCl}\left(\mathrm{LB}_{5}\right)$ at $15^{\circ} \mathrm{C}$ measured as optical density at $410 \mathrm{~nm}$ after $7 \mathrm{~d}$ growth; lipase detected on tributyrin agar; AHLs detected with Chromobacterium violaceum CV026, and Agrobacterium tumefaciens pZLR4. +: positive; (+): slightly positive; -: negative; +/-: majority positive; -/+: majority negative

\begin{tabular}{|c|c|c|c|c|c|c|c|c|}
\hline \multirow[t]{2}{*}{ Strain } & \multirow[t]{2}{*}{ Source } & \multirow[t]{2}{*}{ Location } & \multirow[t]{2}{*}{ Protease } & \multirow[t]{2}{*}{ A-layer } & \multirow[t]{2}{*}{ Pigment } & \multirow[t]{2}{*}{ Lipase } & \multicolumn{2}{|c|}{ AHL production } \\
\hline & & & & & & & CV026 & pZLR4 \\
\hline $\begin{array}{l}\text { ssp. smithia } \\
\text { NCIMB } 13210\end{array}$ & Roach & UK & + & + & 0.12 & - & - & - \\
\hline $\begin{array}{l}\text { ssp. pectinolytica } \\
\text { DSM } 12609\end{array}$ & River water & Argentina & + & - & 6.52 & + & + & + \\
\hline NCIMB 1110 & Sea trout & Scotland & + & - & 0.59 & + & + & + \\
\hline V179 & Wrasse & Scotland & - & - & 0.15 & - & + & - \\
\hline $909 / 81$ & Atlantic salmon & Norway & + & + & 1.46 & $(+)$ & + & + \\
\hline $2013 / 81$ & Atlantic salmon & Norway & - & - & 3.04 & + & + & + \\
\hline $1777 / 92$ & Wolf fish & Norway & + & + & 6.80 & + & + & + \\
\hline $2656 / 92$ & Halibut & Norway & + & + & 1.96 & + & + & + \\
\hline M45/89 & Arctic char & Iceland & + & + & 2.74 & - & + & - \\
\hline S226/90 & Brown trout & Iceland & + & + & 3.10 & $(+)$ & + & + \\
\hline M283/89 & Atlantic salmon & Iceland & + & + & 3.08 & $(+)$ & + & + \\
\hline Т233/91 & Atlantic cod & Iceland & + & + & 3.28 & $(+)$ & + & + \\
\hline T3-A1 & Haddock & Iceland & + & + & 2.64 & $(+)$ & + & + \\
\hline No. 1 & Sea trout & Finland & - & + & 1.73 & + & + & + \\
\hline No. 2 & Brown trout & Finland & - & + & 0.09 & - & - & - \\
\hline No. 3 & Grayling & Finland & - & + & 0.13 & - & - & - \\
\hline $850319-1 / 4$ & Sandeel & Denmark & - & - & 4.56 & $(+)$ & + & + \\
\hline $920225-1 / 2$ & Eel & Denmark & - & + & 0.08 & + & - & - \\
\hline $860613-1 / 1$ & Atlantic salmon & Faroe Islands & - & $-/+$ & 3.02 & - & + & + \\
\hline $329 / 89$ & Atlantic salmon & Sweden & - & + & 0.24 & + & + & - \\
\hline $298 / 89$ & Arctic char & Sweden & - & + & 0.14 & $(+)$ & + & + \\
\hline $420 / 88$ & Brown trout & Sweden & + & + & 1.83 & + & + & + \\
\hline $261 / 89$ & Brown trout & Sweden & - & + & 1.83 & $(+)$ & + & + \\
\hline 870626-1/1 & Blenny & Denmark & + & $+/-$ & 5.08 & $(+)$ & + & + \\
\hline $911025-1 / 2$ & Goldfish & Denmark & - & - & 1.13 & + & - & - \\
\hline $911030-1 / 1$ & Fourbed rockling & Denmark & + & - & 5.16 & - & + & + \\
\hline
\end{tabular}


$N$-(heptylsulfanylacetyl)-L-homoserine lactone (HepSAHL) (Persson et al. 2005) were dissolved in dimethylsulfoxide (DMSO) and stored at room temperature. Aeromonas salmonicida was grown with or without addition of $10 \mu \mathrm{M}$ of ProS-AHL, PenS-AHL and HepSAHL and 0.1\% DMSO (solvent used as control) as described above. Samples were taken at regular intervals for determination of cell density $\left(\mathrm{OD}_{450 \mathrm{~nm}}\right.$ and $\mathrm{CFU} \mathrm{ml} \mathrm{m}^{-1}$ ), pigmentation and protease level.

\section{RESULTS}

\section{Characterization of typical and atypical Aeromonas salmonicida}

AHLs were detected in all 31 of the typical strains and in 21 out of 26 (86\%) of the atypical strains (Tables 1 \& 2) using the monitor strains Agrobacterium tumefaciens and Chromobacterium violaceum. Three atypical strains were only AHL-positive in the $C$. violaceum monitor. Protease activity was detected in 26 out of 31 typical strains and in 13 out of 26 atypical strains. The formation of an A-layer was variable and some strains appeared on CBB-agar-plates with both A-layer positive and A-layer negative colonies. However, only 4 of 31 typical strains and 7 of 26 atypical strains were completely A-layer negative (Tables 1 \& 2). All typical strains produced pigment in liquid cultures resulting in dark brown to nearly black cultures after 3 to $4 \mathrm{~d}$ of aerated incubation. The pigmentation was quantified by OD at $410 \mathrm{~nm}$ and after $7 \mathrm{~d}$ of growth, all of the typical strains showed pigmentation levels corresponding to 4.6 to $7.3 \mathrm{OD}_{410 \mathrm{~nm}}$ (Table 1). The level of pigmentation among most of the atypical strains was much lower between 0.09 and 3.1 $\mathrm{OD}_{410 \mathrm{~nm}}$, except for the strains $1777 /$ 92, 850319-1/4, 870626-1/1, 911030$1 / 1$ and ssp. pectinolytica, which all developed pigmentation to the same extent as the typical strains. Considering the lower growth rate of many of the atypical strains, pigmentation was also measured in these strains after $9 \mathrm{~d}$ of incubation in growth medium; however, this did not alter the pigmentation patterns described above. Of the typical strains, 29 were lipase positive, 19 of 26 atypical strains were positive and of these, several formed only a weak zone on tributyrin agar. All typical strains produced AHLs as detected by the 2 monitor strains, and all but 5 atypical strains produced AHLs. No apparent correlation between AHL production, or any of the potential extracellular virulence factors (protease, A-layer, pigment and lipase) could be detected (Tables $1 \& 2$ ).

\section{Influence of growth conditions on production of virulence factors}

The aerated cultures of Aeromonas salmonicida strain 02-9-1 grew faster and to approximately 10-fold higher level of cell density as compared to those incubated under stagnant conditions (Fig. 1A). The average protease activity of the cultures was $0.45 \Delta \mathrm{OD}_{442 \mathrm{~nm}}$ in the aerated cultures as compared to $0.13 \Delta \mathrm{OD}_{442 \mathrm{~nm}}$ for the static cultures (Fig. 1B). However, considering the lower cell density of the static culture, this corresponds to a higher specific protease activity of the static cultures. No pigment could be detected in the static cultures after $96 \mathrm{~h}$, whereas the aerated cultures were
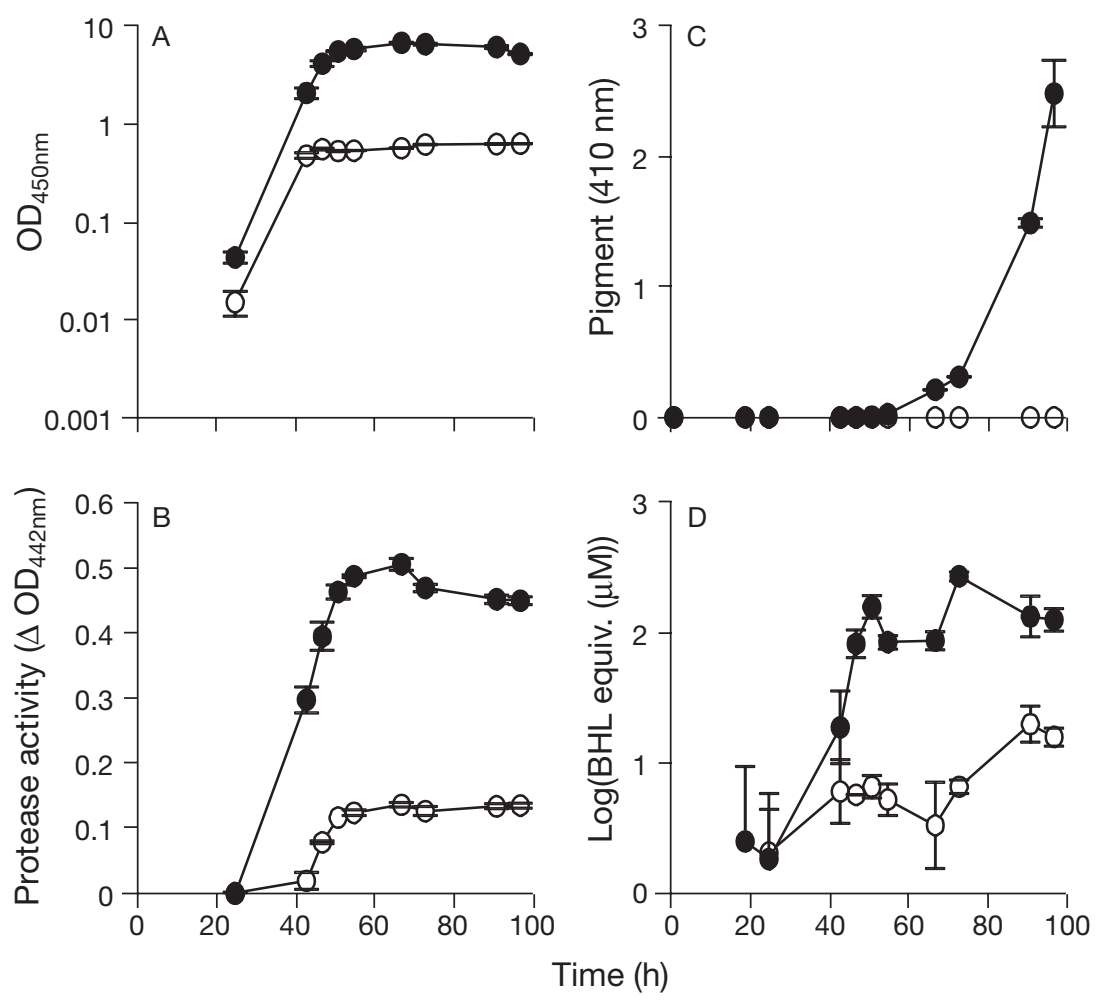

Fig. 1. Aeromonas salmonicida 02-9-1. Effect of aeration on (A) optical density (OD), (B) protease activity, (C) pigment production, and (D) acylated homoserine lactone (AHL) production when grown in Luria-Bertani broth (Bertani 1951) using $5 \mathrm{~g} \mathrm{l}^{-1}$ of $\mathrm{NaCl}\left(\mathrm{LB}_{5}\right)$ at $15^{\circ} \mathrm{C}$, either in static conditions $(\mathrm{O})$ or aerated on a rotational shaker at $200 \mathrm{rpm}(\mathbf{)}$. Values are means \pm SD of double determinations. $\triangle \mathrm{OD}_{442 \mathrm{~nm}}$ : change in $\mathrm{OD}$ at $442 \mathrm{~nm}$; BHL: $N$-butanoyl homoserine lactone 
very darkly pigmented with average pigmentation of $2.48 \mathrm{OD}_{410 \mathrm{~nm}}$ measured on a sterile filtered culture supernatant (Fig. 1C). Even after prolonged incubation for up to $2 \mathrm{wk}$, pigmentation did not develop in the static cultures. According to the semiquantitative well diffusion assay, the concentration of AHLs reached a final level of approximately $5 \mu \mathrm{M} \mathrm{C}_{4}$-HSL equivalents in the aerated cultures, whereas the final level of $\mathrm{C}_{4}$-HSL equivalents in the static cultures was approximately $0.4 \mu \mathrm{M}$ (Fig. 1D). Considering the difference in cell density of a factor 10 , this indicates that the production of AHL per cell unit is similar under both growth conditions. $\mathrm{pH}$ remained at $\mathrm{pH} 7$ in the static cultures but increased to approximately 8.1 after $96 \mathrm{~h}$ of growth under aerated conditions. After prolonged incubation (6 to $7 \mathrm{~d}$ ) cell death and lysis was observed in the aerated cultures probably as a consequence of high $\mathrm{pH}$ (data not shown).

\section{Effect of QSI compounds on growth and protease activity}

The effect of the QSI compounds ProS-AHL, PenSAHL and HepS-AHL on exoprotease production was assessed in $\mathrm{LB}_{5}$ broth at $15^{\circ} \mathrm{C}$. None of the 3 compounds influenced growth of Aeromonas salmonicida 02-9-1 at concentrations of $10 \mu \mathrm{M}$ (Fig. 2A). The protease activity in supernatants from $A$. salmonicida 029-1 grown without QSI compounds was $0.3 \Delta \mathrm{OD}_{442 \mathrm{~nm}}$ after $40 \mathrm{~h}$ whereas the presence of QSI compounds resulted in a significant decrease in protease activity being $0.2,0.09$ and $0.04 \Delta \mathrm{OD}_{442 \mathrm{~nm}}$ for $A$. salmonicida grown with ProS-AHL, PenS-AHL, and HepS-AHL, respectively (Fig. 2B). The magnitude of repression varied depending on the QSI compound; ProS-HSL caused a 1.5-fold decrease, PenS-HSL a 3.3-fold decrease, and HepS-AHL a 7.5-fold decrease. By the end of the experiment (92 $\mathrm{h}$ of incubation) the protease activity of the A. salmonicida culture treated with ProS-AHL had reached the level of the untreated controls $\left(0.42\right.$ to $\left.0.44 \Delta \mathrm{OD}_{442 \mathrm{~nm}}\right)$, whereas the protease activity of the cultures treated with PenS-AHL and HepS-AHL was lower $\left(0.37 \Delta \mathrm{OD}_{442 \mathrm{~nm}}\right)$ (Fig. 2B). Zymograms of sterile filtered supernatants of $A$. salmonicida 02-9-1 growth revealed 5 bands with gelatinolytic activity of approximately 35, 40,58, 91, and $104 \mathrm{kDa}$. When A. salmonicida 02-9-1 was grown in the presence of $10 \mu \mathrm{M}$ HepS-AHL, 3 of these bands $(35,40$, and $58 \mathrm{kDa}$ ) completely disappeared. The $40 \mathrm{kDa}$ band was weak when $A$. salmonicida 02-9-1 was grown with $10 \mu \mathrm{M}$ PenS-AHL as compared to the untreated control, and the bands of 35 and $58 \mathrm{kDa}$ completely disappeared. After $50 \mathrm{~h}$ of growth there was no difference between the gelatinolytic bands for A. salmonicida
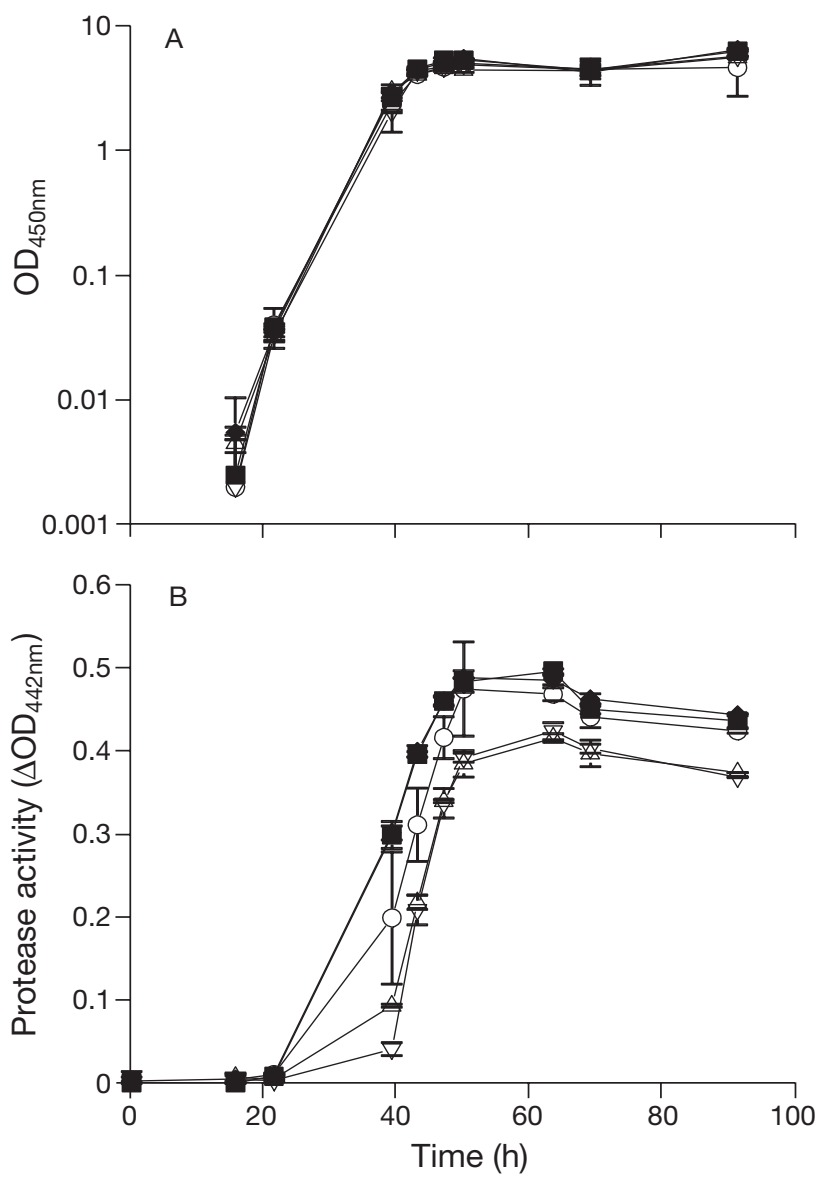

Fig. 2. Aeromonas salmonicida 02-9-1. Effect of the quorum sensing inhibitor compounds $N$-(propylsulfanylacetyl)-Lhomoserine lactone (ProS-AHL), $N$-(pentylsulfanylacetyl)-Lhomoserine lactone (PenS-AHL) and $N$-(heptylsulfanylacetyl)-L-homoserine lactone (HepS-AHL) on (A) optical density (OD) and (B) protease activity when grown in LuriaBertani broth (Bertani 1951) using $5 \mathrm{~g} \mathrm{l}^{-1}$ of $\mathrm{NaCl}\left(\mathrm{LB}_{5}\right)$ broth at $15^{\circ} \mathrm{C}$. $\mathbf{\square}$ : A. salmonicida $02-9-1$; : $02-9-1+0.1 \%$ DMSO; O: $02-9-1+10 \mu \mathrm{M}$ ProS-AHL; $\triangle:$ 02-9-1 + $10 \mu \mathrm{M}$ PenS-AHL; $\nabla:$ 02-9-1 + $10 \mu \mathrm{M}$ HepS-AHL. Values are means $\pm \mathrm{SD}$ of double determinations. $\Delta \mathrm{OD}_{442 \mathrm{~nm}}$ : change in $\mathrm{OD}$ at $442 \mathrm{~nm}$

02-9-1 grown in the presence or absence of the QSI compounds (data not shown). Casein-containing zymogram gels revealed the presence of only one caseinolytic band in sterile filtered supernatants taken after 39 and $50 \mathrm{~h}$ of growth, with an approximately size of $52 \mathrm{kDa}$. This band was present both when $A$. salmonicida 02-9-1 was grown in the presence or absence of the QSI compounds. The 3 QSI compounds had no effect on the pigment production.

\section{DISCUSSION}

Quorum sensing signal molecules were detected in the vast majority of strains in a collection of both typi- 
cal and atypical Aeromonas salmonicida. It has been known for some time that QS systems exist in $A$. salmonicida (Swift et al. 1997), but it has not yet been recognized as a widespread phenomenon which occurrs in most independent isolates. Also, AHL production was widespread in Vibrio anguillarum isolates, where 148 of 150 produced AHLs but no correlation between serotype, virulence or origin could be found (Buch et al. 2003). Recently, Bruhn et al. (2005) found AHL production in all 7 typical A. salmonocida strains investigated, but only in 2 of 10 atypical strains. Furthermore, the 2 atypical strains that produced AHLs were the only 2 atypical strains developing pigmentation and this leads us to hypothesize that AHL production could be involved in regulation of pigment production. However, all of 31 typical and 21 of 26 atypical strains produced AHLs, demonstrating that AHL production in A. salmonicida is widespread, and we did not, on a population basis, find any correlation between AHL production and pigmentation.

Pigmentation has previously been described as being an aerobic phenomenon (Aurstad \& Dahle 1972, Donlon et al. 1983) and we did only detect pigment in the aerated Aeromonas salmonicida cultures. The brownish melanin-like pigments formed by several microorganisms are believed to be a protective mechanism against oxidative radicals of the oxidative burst (de Cassia \& Pombeiro-Sponchiado 2005); hence, it is likely that aeration induces their production. D-glucose may repress pigment formation (Altmann et al. 1992, Koppang et al. 2000), but as all the experiments were performed in $\mathrm{LB}_{5}$ broth, which does not contain glucose, this has not influenced the results. The majority of the atypical strains in this study have been examined for caseinolytic activity by Gudmundsdóttir (1996); except for 3 strains, our reporting of positive and negative strains corresponds to the earlier finding. We did not detect clearing zone on casein agar around 2013/18, 298/89 and 261/89, whereas Gudmundsdóttir (1996) reported low caseinolytic activity for these strains. However, different assays have been used and our casein agar may be slightly less sensitive than the azocasein assay used by Gudmundsdóttir (1996).

The extracellular protease activity was significantly lowered when Aeromonas salmonicida strain 02-9-1 was grown in the presence of the QSI compounds ProSAHL, PenS-AHL and HepS-AHL. As none of these compounds altered growth rate or maximum cell density, the effect is not due to growth repression, and we have previously reported that the compounds do not per se act as protease inhibitors (Rasch et al. 2007). Therefore, the effect of the QSI compounds is believed to be an effect directly on the QS system. PenS-AHL and HepS-AHL also inhibited QS-regulated protease production in a Pectobacterium (Rasch et al. 2006).
Although no apparent connection could be made between the ability to produce AHLs and virulence factors, the fact that known QSI compounds were able to inhibit the production of protease indicate that protease production is under QS regulation in A. salmonicida. Protease production has previously been described as QS-regulated in A. salmonicida, as Swift et al. (1997) observed that addition of exogenous $\mathrm{C}_{4}$-HSL resulted in a small stimulation of protease production, and addition of the longer chained $\mathrm{C}_{10}$-HSL and 3-oxo- $\mathrm{C}_{10}$-HSL inhibited protease production. Also, protease production is QS-regulated in a number of other Gram-negative bacteria such as Pseudomonas aeruginosa, Serratia liquefaciens and Vibrio anguillarum (Passador et al. 1993, Eberl et al. 1996, Croxatto et al. 2002). In P. aeruginosa the QS-regulated gene encoding LasB protease has been repressed by the QSI compounds C-30, patulin, penicillic acid, 4-nitro-pyridine- $N$-oxide and garlic extract (Hentzer et al. 2003, Rasmussen et al. 2005a,b).

Zymograms of supernatants from Aeromonas salmonicida 02-9-1 revealed 5 bands with gelatinolytic activity with molecular sizes of approximately 35, 40, 58, 91, and $104 \mathrm{kDa}$. Arnesen et al. (1995) detected at least 9 bands with molecular weights ranging from 37 to $100 \mathrm{kDa}$, and characterized a gelatinolytic metalloprotease from $A$. salmonicida subsp. salmonicida with a molecular weight of about $37 \mathrm{kDa}$. The major protease activity was found in the bands of 37, 89 and $100 \mathrm{kDa}$ (Arnesen et al. 1995). Considering the accuracy of zymograms for determination of molecular weight it seems likely that these 3 bands correspond to the bands from A. salmonicida 02-9-1 of 35, 91 and $104 \mathrm{kDa}$, respectively. The $35 \mathrm{kDa}$ protease disappeared when $A$. salmonicida was grown in the presence of PenS-AHL and HepS-AHL suggesting that this particular protease is QS-regulated. The protease from A. salmonicida previously described as QS-regulated was a serine protease (Swift et al. 1997) but the molecular weight of the molecule was not determined.

The strategy of blocking quorum sensing for control of fish disease has been explored in recent years. Rasch et al. (2004) showed that the QSI compound furanone C-30 reduced mortality of rainbow trout infected with Vibrio anguillarum, but were not able to explain the effect of C-30 on the identified QS system on the bacteria. $V$. anguillarum strains mutated in the AHL synthase genes were as virulent as the wild type strain when infecting trout (Milton et al. 1997) and the brine shrimp Artemia franciscana (Defoirdt et al. 2005), but the QS system of $V$. anguillarum is extremely complex (Milton 2006), and ensuring a complete inhibition of the QS system is difficult. A mutation in the AHL synthase gene of Aeromonas hydrophila did not have any effect on virulence towards Artemia franciscana (Defoirdt et al. 2005). 
On a population level, AHLs do not appear to be important for regulation of virulence factors in Aeromonas salmonicida and this would indicate that QSI compounds are of little interest in furunculosis control. In contrast, our finding that QSIs can inhibit protease production in a strain of $A$. salmonicida indicates that further studies on the QS regulatory network, its potential involvement in virulence of $A$. salmonicida and the effects of QSI compounds should be pursued.

Acknowledgements: This work was financed by the Danish Technical Research Council under the project 'A new approach to the control of microbial activity' and the research network SCOFDA (Sustainable Control of Fish Diseases in Aquaculture) supported by the Danish Agricultural and Veterinary Research Council and the Danish Ministry of Food, Agriculture and Fisheries. The Agrobacterium tumefaciens monitor was obtained from Dr. Clay Fuqua. The technical assistance of Jacob Dyring Jensen and Jette Melchiorsen is greatly appreciated. We thank Dr. Tobias Persson and Prof. John Nielsen for providing the sulphur-containing AHL analogs.

\section{LITERATURE CITED}

Altmann K, Marshall M, Nicholson SE, Hanna PJ, Gudkovs N (1992) Glucose repression of pigment production in atypical isolates of Aeromonas salmonicida responsible for goldfish ulcer disease. Microbios 72:215-220

Arnesen JA, Eggset G, Jorgensen TO (1995) Partial purification and characterization of extracellular metalloproteases from Aeromonas salmonicida ssp salmonicida. J Fish Dis 18:283-295

Aurstad K, Dahle HK (1972) The production and some properties of the brown pigment of Aeromonas liquefaciens. Acta Vet Scand 13:251-259

Austin B, Austin DA (1999) Bacterial fish pathogens. Diseases of farmed and wild fish. Springer-Praxis Publishing, Chichester

Bernoth EM (1990) Autoagglutination, growth on tryptonesoy-Coomassie-agar, outer membrane protein patterns and virulence of Aeromonas salmonicida strains. J Fish Dis 13:145-155

Bertani G (1951) Studies on lysogenesis. J Bacteriol 62: 293-300

Bruhn JB, Dalsgaard I, Nielsen KF, Buchholtz C, Larsen JL, Gram L (2005) Quorum sensing signal molecules (acylated homoserine lactones) in Gram-negative fish pathogenic bacteria. Dis Aquat Org 65:43-52

Buch C, Sigh J, Nielsen J, Larsen JL, Gram L (2003) Production of acylated homoserine lactones by different serotypes of Vibrio anguillarum both in culture and during infection of rainbow trout. Syst Appl Microbiol 26:338-349

Castang S, Chantegrel B, Deshayes C, Dolmazon R and others (2004) N-sulfonyl homoserine lactones as antagonists of bacterial quorum sensing. Bioorg Med Chem Lett 14: 5145-5149

Cha C, Gao P, Chen YC, Shaw PD, Farrand SK (1998) Production of acyl-homoserine lactone quorum-sensing signals by gram-negative plant-associated bacteria. Mol PlantMicrobe Interact 11:1119-1129

Clark DJ, Maaløe O (1967) DNA replication and division cycle in Escherichia coli. J Mol Biol 23:99-112
Croxatto A, Chalker VJ, Lauritz J, Jass J and others (2002) VanT, a homologue of Vibrio harveyi LuxR, regulates serine, metalloprotease, pigment, and biofilm production in Vibrio anguillarum. J Bacteriol 184:1617-1629

de Cassia RG, Pombeiro-Sponchiado SR (2005) Antioxidant activity of the melanin pigment extracted from Aspergillus nidulans. Biol Pharm Bull 28:1129-1131

Defoirdt T, Bossier P, Sorgeloos P, Verstraete W (2005) The impact of mutations in the quorum sensing systems of Aeromonas hydrophila, Vibrio anguillarum and Vibrio harveyi on their virulence towards gnotobiotically cultured Artemia franciscana. Environ Microbiol 7:1239-1247

Denkin SM, Nelson DR (1999) Induction of protease activity in Vibrio anguillarum by gastrointestinal mucus. Appl Environ Microbiol 65:3555-3560

Depaola A, Peeler JT, Rodrick GE (1995) Effect of oxytetracycline-medicated feed on antibiotic-resistance of Gramnegative bacteria in catfish ponds. Appl Environ Microbiol 61:2335-2340

Donlon J, Mcgettigan S, Obrien P, O'Gara F (1983) Reappraisal of the nature of the pigment produced by Aeromonas salmonicida. FEMS Microbiol Lett 19:285-290

Eberl L, Winson MK, Sternberg C, Stewart GSAB and others (1996) Involvement of N-acyl-L-homoserine lactone autoinducers in controlling the multicellular behaviour of Serratia liquefaciens. Mol Microbiol 20:127-136

Freeman JA, Bassler BL (1999) A genetic analysis of the function of LuxO, a two-component response regulator involved in quorum sensing in Vibrio harveyi. Mol Microbiol 31:665-677

Gram L, Ringø E (2005) Prospects of fish probiotics. In: Holzapfel WH, Naughton PJ (eds) Microbial ecology of the growing animal. Elsevier, Amsterdam, p 379-417

Grave K, Markestad A, Bangen M (1996) Comparison in prescribing patterns of antibacterial drugs in salmonid farming in Norway during the periods 1980-1988 and 1989-1994. J Vet Pharmacol Ther 19:184-191

Gudmundsdóttir BK (1996) Comparison of extracellular proteases produced by Aeromonas salmonicida strains, isolated from various fish species. J Appl Bacteriol 80:105-113

Hentzer M, Wu H, Andersen JB, Riedel K and others (2003) Attenuation of Pseudomonas aeruginosa virulence by quorum sensing inhibitors. EMBO (Eur Mol Biol Org) J 22: 3803-3815

Kim SY, Lee SE, Kim YR, Kim CM and others (2003) Regulation of Vibrio vulnificus virulence by the LuxS quorumsensing system. Mol Microbiol 48:1647-1664

Koch B, Liljefors $T$, Persson $T$, Nielsen J, Kjelleberg $S$, Givskov M (2005) The LuxR receptor: the sites of interaction with quorum-sensing signals and inhibitors. Microbiol 151:3589-3602

Koppang EO, Fjolstad M, Melgard B, Vigerust M, Sorum H (2000) Non-pigment-producing isolates of Aeromonas salmonicida subspecies salmonicida: isolation, identification, transmission and pathogenicity in Atlantic salmon, Salmo salar L. J Fish Dis 23:39-48

Lilley BN, Bassler BL (2000) Regulation of quorum sensing in Vibrio harveyi by LuxO and Sigma-54. Mol Microbiol 36: 940-954

Manefield M, Harris L, Rice SA, de Nys R, Kjelleberg S (2000) Inhibition of luminescence and virulence in the black tiger prawn (Penaeus monodon) pathogen Vibrio harveyi by intercellular signal antagonists. Appl Environ Microbiol 66:2079-2084

Markestad A, Grave K (1997) Reduction of antibacterial drug use in Norwegian fish farming due to vaccination. Dev Biol Standard 90:365-369 
McClean KH, Winson MK, Fish L, Taylor A and others (1997) Quorum sensing and Chromobacterium violaceum: exploitation of violacein production and inhibition for the detection of $\mathrm{N}$-acylhomoserine lactones. Microbiology 143:3703-3711

Milton DL (2006) Quorum sensing in vibrios: complexity for diversification. Int J Med Microbiol 296:61-71

Milton DL, Hardman A, Camara M, Chhabra SR, Bycroft BW, Stewart GSAB, Williams P (1997) Quorum sensing in Vibrio anguillarum: characterization of the vanI/vanR locus and identification of the autoinducer $\mathrm{N}$-(3-oxodecanoyl)-Lhomoserine lactone. J Bacteriol 179:3004-3012

Morohoshi T, Inaba T, Kato N, Kanai K, Ikeda T (2004) Identification of quorum-sensing signal molecules and the LuxRI homologs in fish pathogen Edwardsiella tarda. J Biosci Bioeng 98:274-281

NORM-VET (2004) Consumption of antimicrobial agents and occurrence of antimicrobial resistance in Norway. National Veterinary Institute, Oslo

Passador L, Cook JM, Gambello MJ, Rust L, Iglewski BH (1993) Expression of Pseudomonas aeruginosa virulence genes requires cell-to-cell communication. Science 260: $1127-1130$

Pavan ME, Abbott SL, Zorzopulos J, Janda JM (2000) Aeromonas salmonicida subsp pectinolytica subsp nov., a new pectinase-positive subspecies isolated from a heavily polluted river. Int J Syst Evol Microbiol 50:1119-1124

Persson T, Hansen TH, Rasmussen TB, Skindersoe ME, Givskov M, Nielsen J (2005) Rational design and synthesis of new quorum sensing inhibitors derived from acylated homoserine lactones and natural product from garlic. Org Biomol Chem 3:253-262

Rajmohan S, Dodd CER, Waites WM (2002) Enzymes from isolates of Pseudomonas fluorescens involved in food spoilage. J Appl Microbiol 93:205-213

Rasch M, Buch C, Austin B, Slierendrecht WJ and others (2004) An inhibitor of bacterial quorum sensing reduces mortalities caused by vibriosis in rainbow trout (Oncorhynchus mykiss, Walbaum). Syst Appl Microbiol 27:350-360

Rasch M, Rasmussen TB, Andersen JB, Persson T, Nielsen J, Givskov M, Gram L (2007) Well-known quorum sensing inhibitors do not affect bacterial quorum sensing regulated bean sprout spoilage. J Appl Microbiol 102:826-837

Rasmussen TB, Bjarnsholt T, Skindersoe ME, Hentzer M and 5 others (2005a) Screening for quorum-sensing inhibitors (QSI) by use of a novel genetic system, the QSI selector. J Bacteriol 187:1799-1814

Editorial responsibility: David Bruno,

Aberdeen, UK
Rasmussen TB, Skindersoe ME, Bjarnsholt T, Phipps RK and others (2005b) Identity and effects of quorum-sensing inhibitors produced by Penicillium species. Microbiol 151: $1325-1340$

Ravn L, Christensen AB, Molin S, Givskov M, Gram L (2001) Methods for detecting acylated homoserine lactones produced by Gram-negative bacteria and their application in studies of AHL- production kinetics. J Microbiol Meth 44: $239-251$

Schmidt AS, Bruun MS, Dalsgaard I, Pedersen K, Larsen JL (2000) Occurrence of antimicrobial resistance in fish-pathogenic and environmental bacteria associated with four Danish rainbow trout farms. Appl Environ Microbiol 66: 4908-4915

Smith KM, Bu YG, Suga H (2003) Induction and inhibition of Pseudomonas aeruginosa quorum sensing by synthetic autoinducer analogs. Chem Biol 10:81-89

Spanggaard B, Jorgensen F, Gram L, Huss HH (1993) Antibiotic resistance in bacteria isolated from 3 fresh-water fish farms and an unpolluted stream in Denmark. Aquaculture 115:195-207

Swift S, Karlyshev AV, Fish L, Durant EL and others (1997) Quorum sensing in Aeromonas hydrophila and Aeromonas salmonicida: identification of the LuxRI homologs AhyRI and AsaRI and their cognate N-acylhomoserine lactone signal molecules. J Bacteriol 179:5271-5281

Swift S, Lynch MJ, Fish L, Kirke DF, Tomas JM, Stewart GSAB, Williams P (1999) Quorum sensing-dependent regulation and blockade of exoprotease production in Aeromonas hydrophila. Infect Immun 67:5192-5199

Temprano A, Yugueros J, Hernanz C, Sanchez M, Berzal B, Luengo JM, Naharro G (2001) Rapid identification of Yersinia ruckeri by PCR amplification of yrul-yruR quorum sensing. J Fish Dis 24:253-261

Throup J, Bainton NJ, Bycroft BW, Williams P, Stewart GSAB (1995) Signalling in bacteria beyond luminescence. In: Cambell AK, Kricka LJ, Stanley PE (eds) Bioluminescence and chemiluminescence: fundamental and applied aspects. Wiley, Hoboken, NJ, p 89-92

Tsoumas A, Alderman DJ, Rodgers CJ (1989) Aeromonas salmonicida-development of resistance to 4-quinolone antimicrobials. J Fish Dis 12:493-507

Wiklund T, Dalsgaard I (1998) Occurrence and significance of atypical Aeromonas salmonicida in non-salmonid and salmonid fish species: a review. Dis Aquat Org 32:49-69

Windle HJP, Kelleher D (1997) Identification and characterization of a metalloprotease activity from Helicobacter pylori. Infect Immun 65:3132-3137

Submitted: October 26, 2006; Accepted: November 18, 2006 Proofs received from author(s): November 8, 2007 